\title{
Publisher Correction: Measuring, modelling and projecting coastal land
} \section{subsidence}

Manoochehr Shirzaei(i), Jeffrey Freymueller, Torbjörn E. Törnqvist(i), Devin L. Galloway, Tina Dura (B)

and Philip S. J. Minderhoud D

Correction to: Nature Reviews Earth \& Environment https://doi.org/10.1038/s43017-020-00115-x, published online 10 December 2020.

In Figure 2 of the originally published article, the land subsidence label was pointing to the incorrect line, and GPS signals were incorrectly labelled as $l_{1}$ and $l_{2}$ carriers instead of L1 and L2 carriers. The legend did not define $l$. Both figure and caption have been corrected in the HTML and PDF versions of the manuscript.

https://doi.org/10.1038/s43017-020-00134-8 I Published online 17 December 2020

(c) Springer Nature Limited 2020 